\title{
EGF+61 A>G Polymorphisms and Lung Cancer Risk: Future Directions
}

\section{Ramon Andrade De Mello*}

${ }^{1}$ Department of Medicine, Faculty of Medicine, University of Porto, Alameda Prof Hernani Monteiro, 4200-319, Porto, Portugal

${ }^{2}$ Department of Medical Oncology, Portuguese Oncology Institute, Rua Dr. António Bernardino de Almeida, 4200-072, Porto, Portugal

\author{
Abstract \\ Purpose: This paper will discuss highlight in EGF+61 A>G genetic polymorphism and NSCLC susceptibility. \\ Design: Editorial article \\ Results: Despite controversies results regarding EGF+61 polymorphism and NSCLC risk, recent research showed \\ this association in Portuguese population.
}

Conclusions: As the same as occurred in colorectal cancer, EGF+61 was demonstrated to be associated with NSCLC risk and in a near future may also serve as predictive biomarkers, but further studies are warranted in order to assess this hypothesis.

Keywords: Lung cancer; EGF; Genetic polymorphism; Biomarkers; Non-small-cell lung cancer

\section{Introduction}

Lung cancer accounts more than 1.5 million patients worldwide [1]. It is the leading cancer cause among male, accounting $23 \%$ of total cancer cases and $14 \%$ of cancer deaths [1]. Non-small-cell lung cancer (NSCLC) comprises approximately $80-85 \%$ of lung cancer; and small-cell lung cancer, $15-20 \%$. Adenocarcinoma and squamous cell carcinoma are the most common histological types among NSCLC. To date, many risk factors are associated with lung cancer risk, such as cigar smoking, age, race, gender, randon exposure, wood smoke exposure, environmental and occupational exposure [2]. Genetic influence is a topic that is not completely understandable, but increasing evidence suggests that such factors play important role [3]. Recently, a wide association genome study found that a single nucleotide polymorphism (SNP) at chromosome 13q31.3 was associated with an increased risk of non-small cell lung cancer [4]. Another study also showed that carriers of the most common mutation associated with cystic fibrosis (delta F508) had a decreased incidence of lung cancer compared with controls [5]. Epidermal growth factor (EGF) and its receptor (EGFR) were also demonstrated as a main role in NSCLC carcinogenesis [2]. EGFR tyrosine kinase inhibitors, such as gefitinib [6-8] and erlotinib $[2,9,10]$ showed improved overall survival (OS) and progression free survival (PFS) in NSCLC with EGFR mutation in exon 19 and exon 21 [11]. EGF+61 $\mathrm{A}>\mathrm{G}$ polymorphisms had been demonstrated to be associated with cancer risk in overall $[12,13]$. However, results regarding lung cancer risk remains controversies and limited to Asiatic studies $[14,15]$. Thus, this paper will discuss some highlight concerns regarding $\mathrm{EGF}+61 \mathrm{~A}>\mathrm{G}$ polymorphisms and NSCLC susceptibility.

\section{EGF+61 Polymorphism and Lung Cancer}

Since last decade, EGF $+61 \mathrm{~A}>\mathrm{G}$ polymorphism has been studied as a risk factor of cancer [12]. The first article published showing this association was concerning malignant melanoma [13]. In this work authors also suggested that it could be biologically explained toward the EGF serum higher expression due to the proximity of $+61 \mathrm{G}$ locus to a region involved in EGF gene regulation. Furthermore, EGF+61 A>G polymorphism role was determined in several cancer, such as glioma, [16] prostate cancer, [17] hepatocellular carcinoma, [18] colorectal, [19] esophageal squamous cell carcinoma [20] and gastric cancer [21]. However, in lung cancer results remained in controversies and limited to Asian studies $[14,15]$. Recently, it was showed for the first time in a Portuguese population the association between EGF+61 A>G and $\mathrm{EGF}+61 \mathrm{G}>\mathrm{G}$ genotypes and risk of NSCLC [22]. Nevertheless, this study was in disagreement with Kang et al. [15] that did not reported this association in lung cancer overall. Some concerns could explain those differences in results. First, ethnic divergences may have a role in those divergences. Second, in Kang's study it was compared influence of allele A and risk of lung cancer, considering AG plus AA genotype versus GG genotype. In the Portuguese study [22] it was compared allele G as risk of NSCLC, considering AG and GG genotype versus AA genotype. This fact may be the most important point in this analysis. According to a recent meta-analysis, [12] presence of $\mathrm{G}$ allele is indeed considered as a key point of carcinogenesis steps due to its property of increased serum EGF and therefore stimulate proliferation, angiogenesis, and metastasis $[2,12]$. This interaction between serum EGF and EGFR is very important in NSCLC framework. It induces tumor aggressiveness towards mainly four pathways: 1) Phospholipase C $\gamma$ (PCL- $\gamma)$; 2) Phosphatidylinositol 3-kinase (PI3K); 3) Signal transducer and activator of transcriptions (STATS); and 4) Ras, Raf, MEK, ERK, MAPK (mitogen-activated protein kinase) [2]. Another Korean study conducted by Lim et al. [14] also showed a slight relationship between $\mathrm{EGF}+61 \mathrm{~A}>\mathrm{G}$ polymorphism and lung cancer. However, this study [14] was not statistically strong due to the sample were not in the Hardy-Weinberg equilibrium [12]. Further, in Lim's study [14] the case and control group was not paired by age and sex. The group with lung cancer was much older $(63.5 \pm 10.6$ years) than the healthy control group ( $45.98 \pm 12.19$ years), which means that their control group may have less chances to develop lung cancer than the case group due to be younger.

\section{Current and Future Directions}

Nowadays, NSCLC molecular tools are very important to take in consideration regarding treatment and management decision [23]. EGFR mutation and echinoderm microtubule-associated protein-like 4-anaplastic lymphoma kinase (EML4-ALK) fusion are currently the main tools that medical oncologists have in clinical practice in order

*Corresponding author: Ramon Andrade De Mello, MD, Department of Medicine Faculty of Medicine, University of Porto, Alameda Prof Hernani Monteiro, 4200319, Porto, Portugal, Tel: 351225084 000/ Ext 7323; Fax: 351225084 010; E-mail: ramonmello@med.up.pt

Received July 31, 2012; Accepted August 02, 2012; Published August 02, 2012

Citation: Mello RAD (2012) EGF+61 A>G Polymorphisms and Lung Cancer Risk: Future Directions. J Pulmonar Respirat Med S5:e001. doi:10.4172/2161-105X.S5e001

Copyright: () 2012 Mello RAD. This is an open-access article distributed under the terms of the Creative Commons Attribution License, which permits unrestricted use, distribution, and reproduction in any medium, provided the original author and source are credited. 
to improve NSCLC patients care [2]. Nevertheless, researches do not stop in this field. Target therapies against those mainly molecular pathways and novel biomarkers [24] are object of main interest [2,3]. As it occurred in colorectal cancer (CRC), EGF $+61 \mathrm{~A}>\mathrm{G}$ polymorphism was suggested as involved in NSCLC susceptibility. After, it was demonstrated that $\mathrm{EGF}+61 \mathrm{~A}>\mathrm{G}$ polymorphisms could serve also as a predictive biomarkers for those CRC patients treated with cetuximab [25]. We believe that this is the key point of EGF $+61 \mathrm{~A}>\mathrm{G}$ polymorphism research in lung cancer context. Firstly, determined EGF+61 $\mathrm{A}>G$ polymorphisms with NSCLC susceptibility. Second, test its influence in patient's outcome, assessing where it is possible to serve both as risk either as predictive or prognostic biomarkers. And finally, assess its role in cancer prevention, may be correlating to others risk factors and contributing to creation of nomograms in order to predict cancer risk. This could help in future health public prevention strategies, though many efforts are still warranted to validate those entire issues in others populations.

\section{Statement of Translational Relevance}

Recently, Studies in EGF+61 A>G polymorphism field showed its relevance in cancer behavior. EGF+61 genotypes role was determined in several cancers, such as gliomas, gastric and colorectal cancer (CRC). In 2011, it was demonstrated that this polymorphism could also serve as predictive biomarker for CRC patients treated with cetuximab. In lung cancer results remain limited and controversy. Thus, this article will provide a point of view and discuss relevant issues in this framework.

\section{References}

1. Jemal A, Bray F, Center MM, Ferlay J, Ward E, et al. (2011) Global cancer statistics. CA Cancer J Clin. 61: 69-90.

2. de Mello RA, Marques DS, Medeiros R, Araujo AM (2011) Epidermal growth factor receptor and K-Ras in non-small cell lung cancer-molecular pathways involved and targeted therapies. World J Clin Oncol 2: 367-376.

3. de Mello RA, Costa BM, Reis RM, Hespanhol V (2012) Insights into Angiogenesis in Non-Small Cell Lung Cancer: Molecular Mechanisms, Polymorphic Genes, and Targeted Therapies. Recent Pat Anticancer Drug Discov 7: 118-131.

4. Li Y, Sheu C, Ye Y, de Andrade M, Wang L, et al. (2010) Genetic variants and risk of lung cancer in never smokers: a genome-wide association study. Lancet Oncol 11: 321-330.

5. Li Y, Sun Z, Wu Y, Babovic-Vuksanovic D, Li Y, et al. (2010) Cystic fibrosis transmembrane conductance regulator gene mutation and lung cancer risk. Lung Cancer 70: 14-21.

6. Maemondo M, Inoue A, Kobayashi K, Sugawara S, Oizumi S, et al. (2010) Gefitinib or chemotherapy for non-small-cell lung cancer with mutated EGFR. N Engl J Med 362: 2380-2388.

7. Mok TS, Wu YL, Thongprasert S, Yang CH, Chu DT, et al. (2009) Gefitinib or carboplatin-paclitaxel in pulmonary adenocarcinoma. N Engl J Med 361: 947957.

8. Mitsudomi T, Morita S, Yatabe Y, Negoro S, Okamoto I, et al. (2010) Gefitinib versus cisplatin plus docetaxel in patients with non-small-cell lung cancer harbouring mutations of the epidermal growth factor receptor (WJTOG3405): an open label, randomised phase 3 trial. Lancet Oncol 11: 121-128.

9. Cappuzzo F, Ciuleanu T, Stelmakh L, Cicenas S, Szczesna A, et al. (2010) Erlotinib as maintenance treatment in advanced non-small-cell lung cancer: a multicentre, randomised, placebo-controlled phase 3 study. Lancet Oncol 11: 521-529.

10. Zhou C, Wu YL, Chen G, Feng J, Liu XQ, et al. (2011) Erlotinib versus chemotherapy as first-line treatment for patients with advanced EGFR mutationpositive non-small-cell lung cancer (OPTIMAL, CTONG-0802): a multicentre, open-label, randomised, phase 3 study. Lancer Oncol 12: 735 -742.

This article was originally published in a special issue, Lung Cancer Challenges to the future handled by Editor(s). Dr. Ramon Andrade de Mello, University of Porto, Portugal
11. Paez JG, Janne PA, Lee JC, Tracy S, Greulich H, et al. (2004) EGFR mutations in lung cancer: correlation with clinical response to gefitinib therapy. Science 304: 1497-1500.

12. Zhang YM, Cao C, Liang K (2010) Genetic polymorphism of epidermal growth factor $61 \mathrm{~A}>\mathrm{G}$ and cancer risk: a meta-analysis. Cancer Epidemiol 34: 150-156.

13. Shahbazi M, Pravica V, Nasreen N, Fakhoury H, Fryer AA, et al. (2002) Association between functional polymorphism in EGF gene and malignant melanoma. Lancet 359: 397-401.

14. Lim YJ, Kim JW, Song JY, Hong MS, Jin SY, et al. (2005) Epidermal growth factor gene polymorphism is different between schizophrenia and lung cancer patients in Korean population. Neurosci Lett 374: 157-160.

15. Kang HG, Choi JE, Lee WK, Kam S, Cha SI, et al. (2007) +61A>G polymorphism in the EGF gene does not increase the risk of lung cancer. Respirology 12: 902905.

16. Costa BM, Ferreira P, Costa S, Canedo P, Oliveira P, et al. (2007) Association between functional EGF+61 polymorphism and glioma risk. Clin Cancer Res 13: $2621-2626$.

17. Teixeira AL, Ribeiro R, Cardoso D, Pinto D, Lobo F, et al. (2008) Genetic polymorphism in EGF is associated with prostate cancer aggressiveness and progression-free interval in androgen blockade-treated patients. Clin Cancer Res 14: 3367-3371.

18. Tanabe KK, Lemoine A, Finkelstein DM, Kawasaki H, Fujii T, et al. (2008) Epidermal Growth Factor Gene Functional Polymorphism and the Risk of Hepatocellular Carcinoma in Patients With Cirrhosis. JAMA 299: 53-60.

19. Wu GY, Hasenberg T, Magdeburg R, Bönninghoff R, Sturm JW, et al. (2009) Association between EGF, TGF-beta1, VEGF gene polymorphism and colorectal cancer. World J Surg 33: 124-129.

20. Cui L, Pan XM, Ma CF, Shang-Guan J, Yu HB, et al. (2010) Association Between Epidermal Growth Factor Polymorphism and Esophageal Squamous Cell Carcinoma Susceptibility. Dig Dis Sci 55: 40-45.

21. Araújo AP, Costa BM, Pinto-Correia AL, Fragoso M, Ferreira P, et al. (2011) Association between EGF +61A/G polymorphism and gastric cancer in Caucasians. World J Gastroenterol 17: 488-492.

22. de Mello RA, Ferreira M, Costa BM, Pires FS, Neves I, et al. (2011) 9139 POSTER Association Between +61 A/G Polymorphism in the EGF Gene and Non-Small Cell Lung Cancer Risk in Male Caucasians. Eur J Cancer 47: S635.

23. Brugger W, Triller N, Blasinska-Morawiec M, Curescu S, Sakalauskas R, et al. (2011) Prospective molecular marker analyses of EGFR and KRAS from a randomized, placebo-controlled study of erlotinib maintenance therapy in advanced non-small-cell lung cancer. J Clin Oncol 29: 4113-4120.

24. Araujo A, Ribeiro R, Azevedo I, Coelho A, Soares M, et al. (2007) Genetic polymorphisms of the epidermal growth factor and related receptor in non-small cell lung cancer--a review of the literature. Oncologist 12: 201-210.

25. Hu-Lieskovan S, Vallbohmer D, Zhang W, Yang D, Pohl A, et al. (2011) EGF61 Polymorphism Predicts Complete Pathologic Response to Cetuximab-Based Chemoradiation Independent of KRAS Status in Locally Advanced Rectal Cancer Patients. Clin Cancer Res 17: 5161-5169. 